\title{
Basic rockfall simulation with consideration of vegetation and application to protection measure
}

\author{
H. Masuya ${ }^{1}$, K. Amanuma ${ }^{2}$, Y. Nishikawa ${ }^{2}$, and T. Tsuji ${ }^{3}$ \\ ${ }^{1}$ Faculty of Environmental Design, Institute of Science and Engineering, Kanazawa University, Ishikawa, Japan \\ ${ }^{2}$ Division of Environmental Science and Engineering, Graduate School of Natural Science and Technology, Kanazawa \\ University, Ishikawa, Japan \\ ${ }^{3}$ Arusu Consultant Co., Ltd., Ishikawa, Japan
}

Received: 31 January 2009 - Revised: 28 August 2009 - Accepted: 8 October 2009 - Published: 10 November 2009

\begin{abstract}
The estimation of risk due to rockfall is often done empirically. As a rational and effective method towards performance-based design of protection measures, a threedimensional simulation method helps to describe the motion of rockfall on a slope and to consider the effect of vegetation probabilistically. This document details a typical simulation method and analyses the manner of rockfalls paired with interference of vegetation and other factors. As application, an actual slope is analyzed where rockfall occurred during the Noto Peninsula Earthquake. Finally, the validity and the benefits of the shown method are the basis for a hazard mapping for rockfall and the planning of measures.
\end{abstract}

\section{Introduction}

Roads and railways passing through steep slopes are exposed to risks imposed by natural hazards, such as landslides, rockfalls and avalanches. Regarding rockfalls, occurrence position on the slope and movement, its kinetic energy and possible impact forces are required to plan protection measures (Japan Railway Civil Engineering Association, 1978; Impact Committee of Japan Society of Civil Engineers, 1998; Japan road association, 2000; Yoshida et al., 1985; Kishi et al., 1993; Sonoda, 1993; Masuya and Yamamoto, 1999; Montani et al., 1999; Masuya and Nakata, 2002; Delhomme, 2005; Schellenberg, 2009). In most cases, rockfall occurs accidentally. The problems regarding rockfalls can be classified into four categories as shown in Table 1 (Ishikawa, 1999). At present, to predict the occurrence of a rockfall event is generally quite difficult, because useful and sufficient data is mostly not available. However, information related to the location and the frequency of already occurred rockfalls in the

Correspondence to: H. Masuya (masuya@kenroku.kanazawa-u.ac.jp) field can be obtained. When measures against rockfalls are investigated, the run out distance of the rockfall trajectory and the collision velocity are the significant items.

On the other hand, the concrete ultimate limit states of protection structures under rockfall impact and general dynamic behaviors up to them are mostly not clarified sufficiently. Therefore, further development of prevention technologies for hazards and improvements in the design method of protection structures are mandatory. It can be expected that performance based design approach will results in a better selection of the most efficient and economical protection structures (Subcommittee for Performance Based Design of Structures against Impact Action, 2007; Masuya, 2008).

There are three major challenges in properly selecting measures for rockfall protection. One is how to perform the risk estimation of rockfall. The second is to set up limit states and design criteria for each protection structure according to the estimated risk. Third is how to utilize new protection technology and verify its performance.

In order to cover the first challenge mentioned above. A technique to analyze the motion of rockfall on a three dimensional slope is needed, aiming for establishing of a more practical simulation. This paper therefore shows the basic theories of the rockfall motion and the numerical analysis methods with a probabilistic consideration of vegetation on the slope. Furthermore, the validity and the applicability of this technique are shown using an example for an actual slope.

\section{Simulation method}

\subsection{Estimation of the rockfall motion}

In Japan, the velocity of a rockfall is empirically expressed by (Japan road association, 2000) by

$V=\alpha \cdot \sqrt{2 g H}$.

Where, $H$ is vertical height of rockfall, $g$ is acceleration of 
Table 1. Classification of tasks concerning rockfalls.

\begin{tabular}{ll}
\hline $\begin{array}{l}\text { Classification } \\
\text { of rockfalls }\end{array}$ & Content \\
\hline Occurrence & $\begin{array}{l}\text { Predictions of time, } \\
\text { location and scale } \\
\text { concerning occurrence }\end{array}$ \\
Motion on slope & $\begin{array}{l}\text { Predictions of location } \\
\text { and velocity }\end{array}$ \\
Impact action & $\begin{array}{l}\text { Estimations of energy and/or } \\
\text { force that should be considered } \\
\text { as role of protection structure. }\end{array}$ \\
Dynamic behavior & $\begin{array}{l}\text { Several states of protection } \\
\text { structures according to the energy } \\
\text { of action level of the rockfalls. }\end{array}$ \\
\hline structures &
\end{tabular}

(a) Velocity estimation

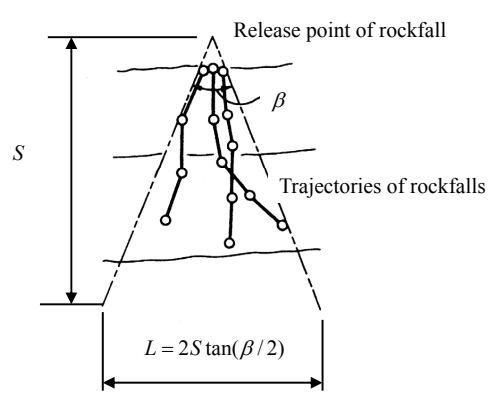

(b) Attainment range

Fig. 1. Velocity estimation and attainment range of rockfalls at slope foot.

gravity, $\alpha$ is a residual coefficient of velocity. If it is assumed that a rock slides on an equivalent straight slope with a gradient $\theta$, the residual coefficient $\alpha$ is expressed using $\theta$ and an equivalent frictional coefficient between rock and slope $\mu$ as shown in Fig. 1a:

$\alpha=\sqrt{1-\frac{\mu}{\tan \theta}}$

Table 2 shows the recommended equivalent coefficients of friction for various conditions, which were collected from past experiments (Japan road association, 2000). The velocity of the rockfall can be determined according to this recommendation. The friction coefficient is chosen according

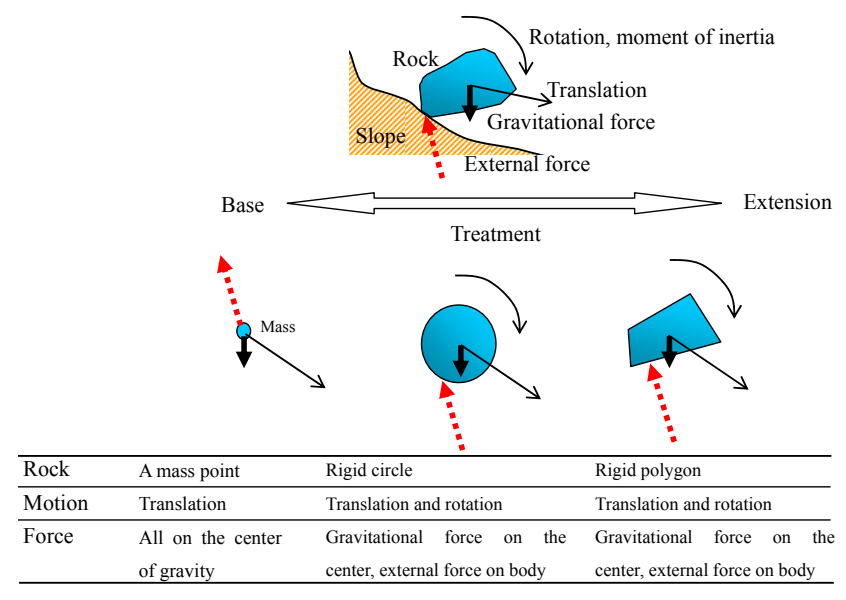

Fig. 2. Concept of kinetic treatment of rockfall in 2-D simulation.

to the characteristics shown in Table 2 without any relation to the size and the actual movement of a rock such as rolling or bouncing. However, there is not enough data regarding the situations where there is relevant vegetation on the slope or not. Only the sideward spread of possible trajectories at the slope foot is empirically determined by angle $\beta$ as shown in Fig. 1b.

In simple simulations for the motion of a rockfall, the rock is assumed to be a point mass (i.e. mass without volume), a cylindrical or a spherical rigid body (Pfeiffer et al., 1990; Stevens, 1998). Motions such as jump, collision, slide or rotation of the falling rock are treated in consideration of the reaction forces with the slope. The kinetic equations expressing the motion of a rock are generally solved by successive numerical integration over the time.

Figure 2 shows the concept of kinetic modeling of shape, motion and the forces considered for a simulated rockfall. The left part of this figure shows that the shape and expansion of a rock and hence its rotation are disregarded. For more comprehensive modeling, it is possible to analyze also the rock's rotation, the action position of external forces and the rock shape (Shi, 1990; Barrett, 1989; Azzoni, 1995).

\subsection{Consideration of the influence of vegetation}

On slopes of mountain areas with risks of rockfalls, vegetation usually exists in many cases. It is known that vegetation is very effective against natural hazards, such as landslides and rockfalls. The protective effect of mountain forests against rockfall was shown using a 3-D simulation model by Stoffel et al. (2006). The energy reduction effect of vegetation was studied experimentally in very detail by Dorren et al. (2005). And an overview of the current scientific knowledge and methods concerning rockfalls and forests protecting against them were shown by Dorren et al. (2007). The energy absorption of trees using numerical singletree model was investigated by Jonsson (2007), but there are still many 
Table 2. Equivalent coefficients of friction.

\begin{tabular}{|c|c|c|}
\hline Classification & Characteristics of slope and rock & $\begin{array}{l}\text { Recommended equivalent coefficient } \\
\text { of friction } m u \text { (experimental value) }\end{array}$ \\
\hline A & $\begin{array}{l}\text { Hard rock, small roughness, no vegetation. } \\
\text { Round rock }\end{array}$ & $\begin{array}{l}0.05 \\
\text { (under } 0.10)\end{array}$ \\
\hline B & $\begin{array}{l}\text { Soft rock, medium roughness, no vegetation. } \\
\text { Round or squarish rock. }\end{array}$ & $\begin{array}{c}0.15 \\
(0.11-0.20)\end{array}$ \\
\hline $\mathrm{C}$ & $\begin{array}{l}\text { Soil and sand slope, small or medium roughness, } \\
\text { no vegetation. Round or squarish rock. }\end{array}$ & $\begin{array}{c}0.25 \\
(0.21-0.30)\end{array}$ \\
\hline $\mathrm{D}$ & $\begin{array}{l}\text { Talus slope, medium or large roughness, } \\
\text { with vegetation or no vegetation. Squarish rock. }\end{array}$ & $\begin{array}{c}0.35 \\
\text { (over } 0.31)\end{array}$ \\
\hline
\end{tabular}

problems to be solved about evaluation of the role of vegetation against rockfalls.

However, the simulation of large trees on a slope can be performed comparatively easily, if the positions and the characteristics of the trees are identified. Therefore, when the risk of rockfalls is estimated, the influence of vegetation is not taken into account in most cases in order to raise the safety level. In general, dealing with the existence of vegetation as a probability factor is probably the only rational and realistic solution to evaluate the risk of rockfalls in a large-scale slope with vegetation.

\subsection{Numerical modeling}

However, it is difficult to solve the motion equation and to truly reflect the interaction of a real rock with complex surface. Therefore, as a convenient simplification, a spherical shape of the rock is assumed. This assumption again is on the safe side, because a sphere guarantees highest velocities and energies.

Different motion patterns are taken into consideration, as well as the modeling of the irregular nature as an important influence factor (Stevens, 1998). An actual slope has various irregularities on its surface, and it is almost impossible to model these irregularities perfectly. For this reason, only large changes in surface are taken into consideration in this study and small irregularities are disregarded. The irregular behavior is then expressed by assigning a coefficient of restitution and a coefficient of friction as probability variables (Masuya et al., 1997).

The slope is divided and modeled by triangular planes as shown in Fig. 3. If it is assumed that the slope is expressed with $n_{s}$ triangle planes and $n_{p}$ nodal points, the arbitrary triangle plane of a slope is expressed by

$a X+b Y+Z=d$

Where, $a, b$, and $d$ are constants. If the vertexes of a triangle plane are set to $i\left(\begin{array}{llll}X_{i} & Y_{i} & Z_{i}\end{array}\right), j\left(\begin{array}{llll}X_{j} & Y_{j} & Z_{j}\end{array}\right)$ and
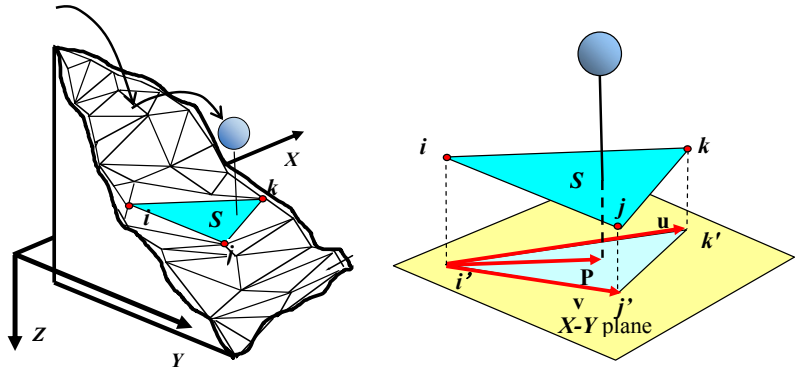

Fig. 3. Modeling of a slope as an assemble of triangle planes and a projected triangle plane to $\mathrm{X}-\mathrm{Y}$ plane under the rock.

$k\left(\begin{array}{lll}X_{k} & Y_{k} & Z_{k}\end{array}\right)$, the plane is expressed by

$a=\frac{\left(Z_{i}-Z_{k}\right)\left(Y_{i}-Y_{j}\right)-\left(Z_{i}-Z_{j}\right)\left(Y_{i}-Y_{k}\right)}{\left(X_{i}-X_{j}\right)\left(Y_{j}-Y_{k}\right)-\left(X_{i}-X_{k}\right)\left(Y_{i}-Y_{j}\right)}$

$b=\frac{\left(Z_{i}-Z_{k}\right)\left(X_{i}-X_{j}\right)-\left(Z_{i}-Z_{j}\right)\left(X_{i}-X_{k}\right)}{\left(Y_{i}-Y_{j}\right)\left(X_{i}-X_{k}\right)-\left(Y_{i}-Y_{k}\right)\left(X_{i}-X_{j}\right)}$

$d=a X_{i}+b Y_{i}+Z_{i}$.

In order to analyze the movement of a rockfall, it is necessary to know on which slope triangle the rock is at the considered time. When a rockfall moves over a triangle plane $S$ as shown in Fig. 3, the vectors $\boldsymbol{u}$ and $\boldsymbol{v}$ are considered in the plane $S^{\prime}$ projected on the $X-Y$ plane of $S$. The vector $\boldsymbol{u}$ from point $i^{\prime}$ to point $j^{\prime}$ and the vector $v$ from point $i^{\prime}$ to point $k^{\prime}$ are expressed as

$\boldsymbol{u}=\left(\begin{array}{lll}X_{j}-X_{i} & Y_{j}-Y_{i} & 0\end{array}\right)$

$\boldsymbol{u}=\left(\begin{array}{lll}X_{j}-X_{i} & Y_{j}-Y_{i} & 0\end{array}\right)$

If the vector $\boldsymbol{P}$ from point $\boldsymbol{i}^{\prime}$ to the vertically projected point of the rock satisfies the following formula, it can be determined that the rock is above this triangle.

$\boldsymbol{P}=t \boldsymbol{u}+s \boldsymbol{v}$

Where, $t, s \geq 0$ and $t+s \leq 1$. 


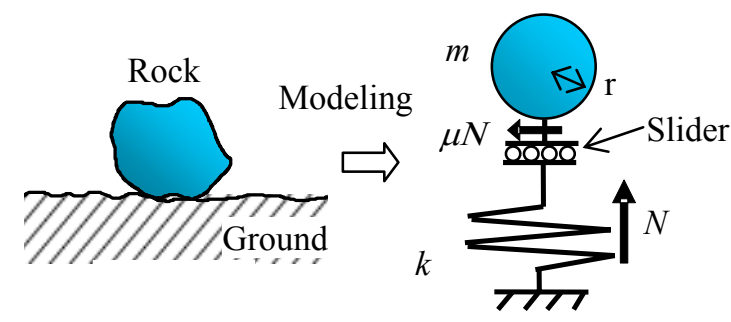

$k$ : Spring constant

$m:$ Mass of rock

$N$ : Normal direction force (compression only)

$\mu$ : Coefficient of friction

$r$ : Radius of rock

Fig. 4. Contact model between rockfall and slope.

When it can be confirmed that the rock is located above a certain triangle of the slope by Eq. (6), it can be easily determined whether the rock is in contact with the slope by

$\frac{\left|a X_{r}+b Y_{r}+Z_{r}-d\right|}{\sqrt{a^{2}+b^{2}+1}} \leq r$.

Where, $r$ is the radius of the assumed to be a spherical rock. $X_{r}, Y_{r}$, and $Z_{r}$ are the coordinates of the center of the rock. $a, b$, and $d$ define the equation of the slope (see Eq. $4 \mathrm{a}, \mathrm{b}$, and $\mathrm{c}$ ).

The left side of Eq. (7) is the perpendicular distance from a rock center to a slope. When it is smaller than the radius, the rock is in contact with the slope. It is assumed that the rock always is above or on a slope. Figure 4 shows the model between rockfall and slope. It is assumed that a rock receives a normal force $N$ and a tangential direction force $F$ from a slope at the time of collision between the rock and the slope. The contact forces $N$ and $F$ are calculated by this contact model. The change of translational velocity $\Delta v_{t d r}$ parallel to the slope and the change of rotational velocity $\Delta \omega_{r}$ are calculated by

$\Delta v_{t d r}=\frac{\int_{0}^{T_{c}} F d t}{m}$

$\Delta \omega_{r}=\frac{\int_{0}^{T_{c}} F r d t}{I}$.

Where, $m$ and $I$ are the mass and the moment inertia of the rock, $T_{C}$ is the contact time of the rock and the slope (Masuya et al., 1997).

The trees used as vegetation are illustrated on Fig. 5. A tree is expressed using three simple parameters: height $h_{t}$ $(\mathrm{m})$, diameter $\phi_{t}(\mathrm{~m})$ and density of trees $\rho_{0}\left(\right.$ number $\left./ \mathrm{m}^{2}\right)$ as shown in Fig. 5. These parameters can be used for probabilistic calculations.

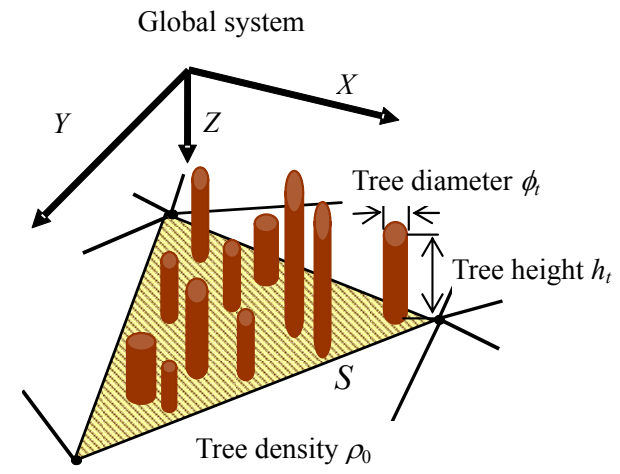

Fig. 5. Modeling of trees.

In addition, it is assumed that all trees are standing perpendicular to the X-Y plane in the global coordinate system. Each tree is modeled as a rigid body that has no branches and no leaves.

When rockfall occurs over a certain slope, the jump height $h$, namely the distance from the slope to the rock center is expressed the same as the left term of Eq. (7):

$h=\frac{\left|a X_{r}+b Y_{r}+Z_{r}-d\right|}{\sqrt{a^{2}+b^{2}+1}}$

When the vertical distance from the slope to the rock center is set to $h_{r}$, it can be expressed by

$h_{r}=\frac{h}{\cos \theta}$.

Figure 6 a illustrates this relationship.

When $h_{r}$ is larger than the height of a tree, there is no possibility of a collision between the rock and the tree. However, when $h_{r}$ is smaller than the height of a tree, there is possibility for collision. The probability density of trees $\rho$ with heights larger than $h_{r}$ is expressed by the following equation under the assumption of Gaussian distribution.

$\rho=\rho_{0} \int_{h_{r}}^{\infty} f_{x}(h) d h=\rho_{0} \frac{1}{\sigma_{h_{t}} \sqrt{2} \pi} \int_{h_{r}}^{\infty} \operatorname{EXP}\left[-\frac{1}{2}\left(\frac{h-M_{h_{t}}}{\sigma_{h_{t}}}\right)^{2}\right] d h$

Where $M_{h_{t}}$ and $\sigma_{h_{t}}$ are the mean value and the standard deviation related to the height of trees. The number of the trees collided with the falling rock during the time $\Delta t$ is given by the following equation considering the domain shown in Fig. 7 and corresponds to the probability of collision.

$n_{t}=\rho\left(\phi_{r}+\phi_{t}\right) v \Delta t$

Where, $\phi_{r}$ and $\phi_{t}$ are diameters of the rock and a tree. $v$ is the velocity of the rock.

When a rockfall collides with a tree on the slope as shown in Fig. 6b, a normal force perpendicular to plane $\pi$ and a frictional force in plane $\pi$ are assumed by a similar manner as between the rock and the slope with different coefficients (see Fig. 4 and Eq. 7). Generally, branches and leaves of 


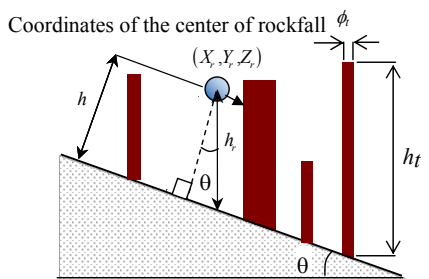

(a) Vertical height of a rock and height of tree

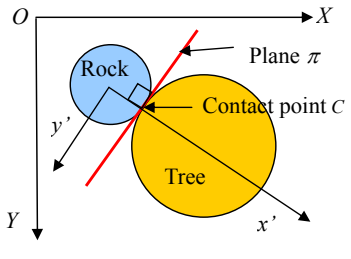

(b) Contact between rockfall and tree

Fig. 6. Rockfall and trees on slope.

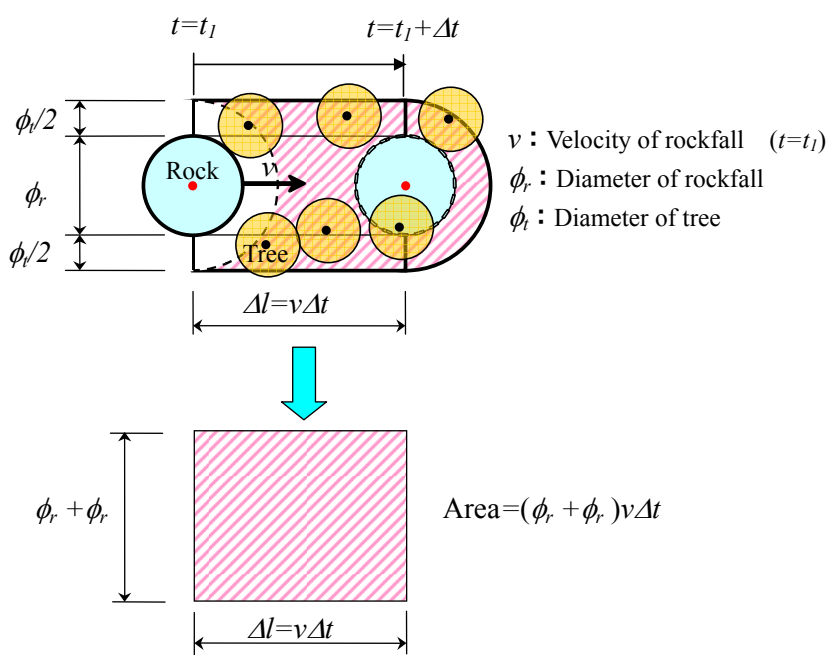

Fig. 7. Domain with possibility of contact with trees.

the trees also absorb some of the rocks energy. In order to simplify and to be on the safe side, those influences can be disregarded in a first attempt. Also it was assumed that there is no deformation of the tree trunk. Advanced research also consider the influence by the destruction of trunks, branches and leaves at best pained with accumulation of fundamental data (Wieczorek, 2000).

Figure 8 shows the flowchart of the complete simulation used in this study. The treatment of the collision between a rock and a slope and various coefficients were shown in Masuya et al. $(1997,2002)$ and Komura et al. (2001).

\section{Application on a real slope}

\subsection{Simulations and hazard assessment}

The Suzu-Maura area on Noto Peninsula in Japan is not only known as a scenic spot, but also as a dangerous zone, in which rockfall occurs frequently. Figure 9 shows the topographical map of the mountain used for slope analysis. At the foot of the slope the national road No. 249 passes along the coastline.

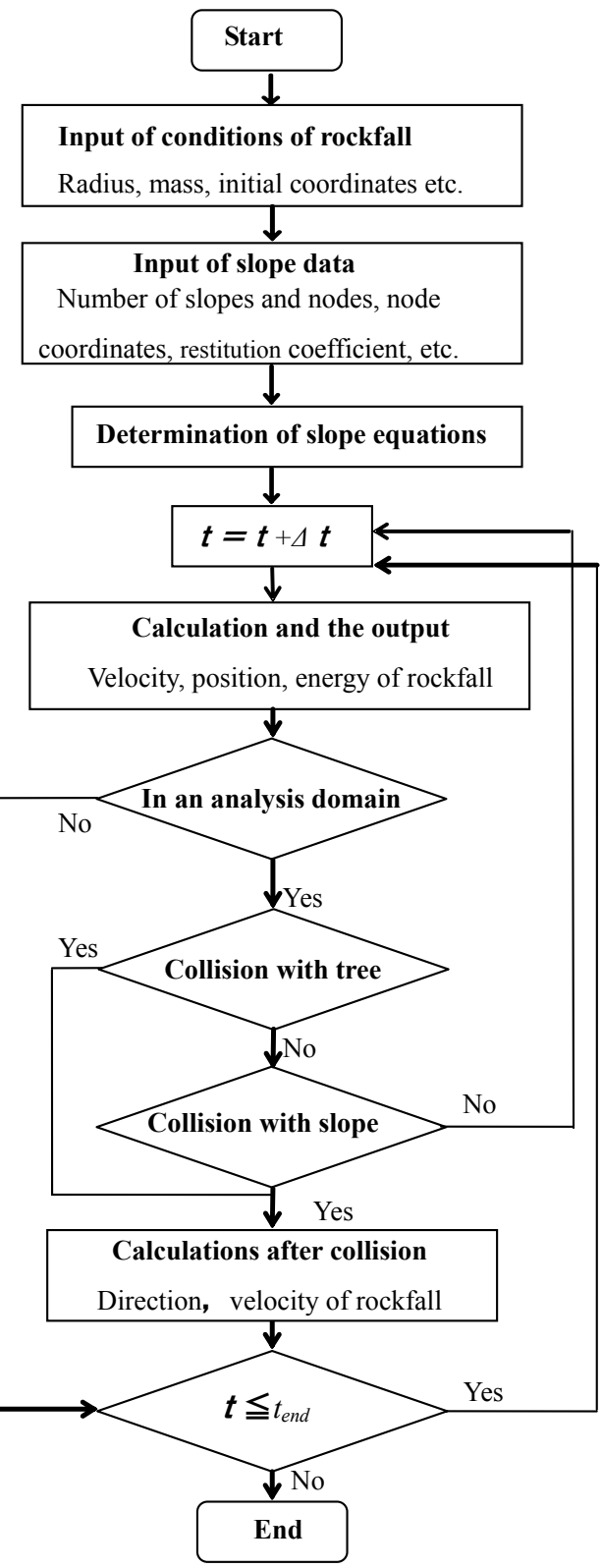

Fig. 8. Flowchart of simulation.

It was considered that a rock with a mass of $4500 \mathrm{~kg}$ mass falls from the upper end of the slope, at a height of $Z=175 \mathrm{~m}$. The mean coefficient of restitution between the rock and slope is 0.15 and its standard deviation is 0.05 . The mean coefficient of friction is 0.3 with a standard deviation of 0.05 . A basic three-dimensional simulation itself is given in Masuya et al. (1997). The values used in here are taken from previous investigations (Masuya et al., 2001; Komura et al., 2001). There is vegetation on most parts of the slope. Three constant parameters related to the trees as slope vegetation, namely height $h_{t}=5.0 \mathrm{~m}$, diameter $\phi_{t}=0.2 \mathrm{~m}$ and density of trees $\rho_{0}=0.01$ trees $/ \mathrm{m}^{2}$ were used. 


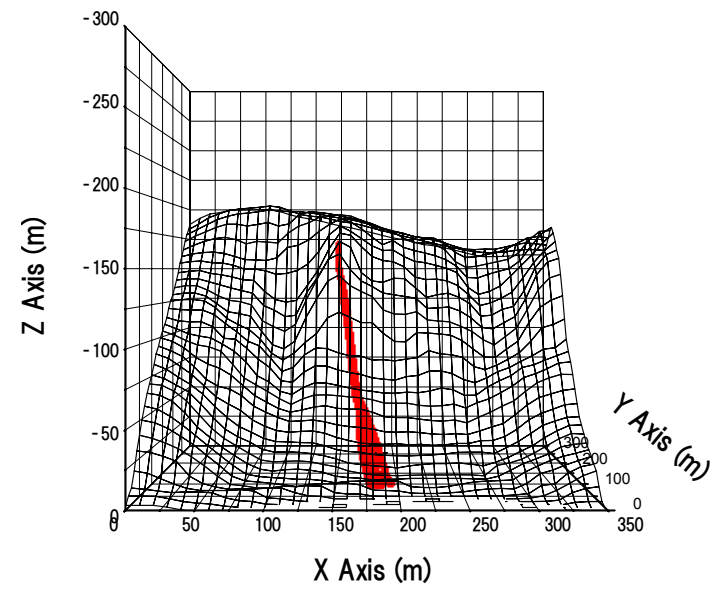

(a) Trajectories without trees on slope

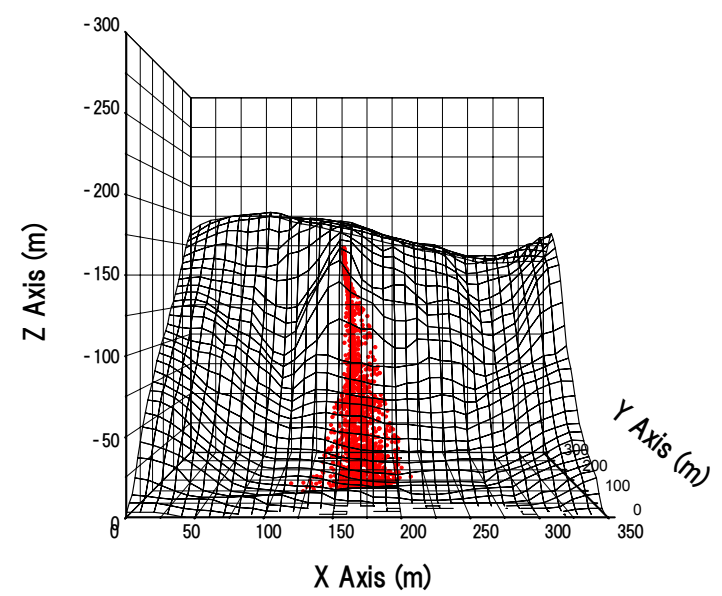

(b) Trajectories with trees on slope

Fig. 9. The mountain slope used for simulation of rockfall and trajectories of rockfalls.

The simulation was iterated 100 times for both cases with and without trees on the slope. The calculated trajectories are shown in Fig. 9. It can be confirmed that all rockfalls reach the coastline regardless of the existence of trees on the slope. Further, it can be noted that the spread of the rockfalls for the case with trees is larger than without trees. The spread represents the endangered zone for rockfalls. The velocities at the mountainside of the road is the relevant information for hazard prevention.

Figure 10a shows the distributions of $X$ coordinates of the rockfalls that reached the mountainside of the road. The average value of $X$ was approximately $170 \mathrm{~m}$, regardless the existence of trees on the slope. The final locations of rockfall concentrate on a narrow range of about $4 \mathrm{~m}$ in $\mathrm{X}$ direction for the case without trees on the slope. On the other hand, those values were distributed fairly large ranging $X=140 \mathrm{~m}$ to $X=210 \mathrm{~m}$ for the case with trees on the slope.
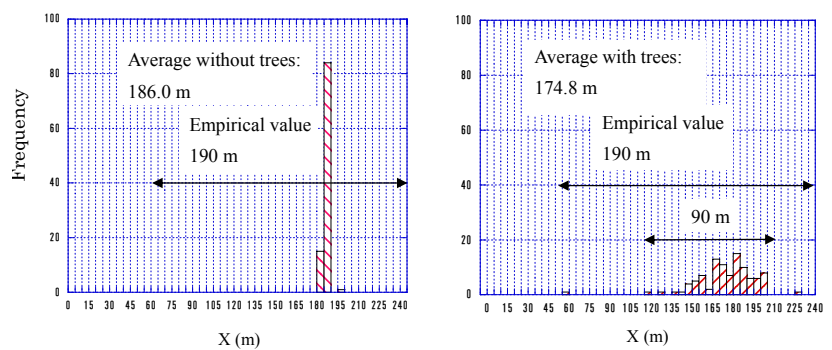

(a) Location $X$ of rockfalls
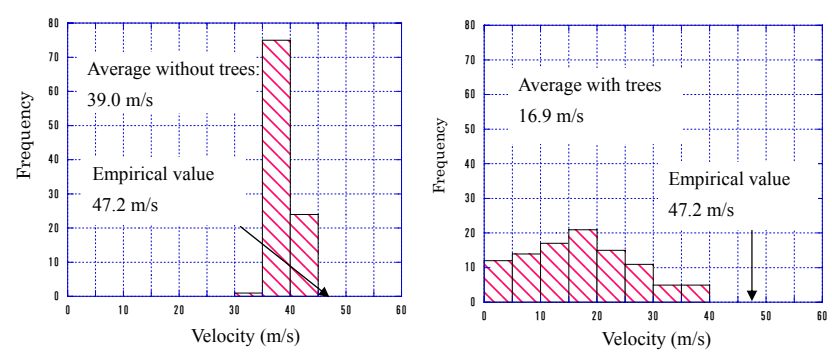

(b) Velocity of rockfalls

Fig. 10. Final distribution along road (X-direction) and velocity of rockfalls at the mountainside of the road.

The width of dangerous zone for rockfalls becomes $190 \mathrm{~m}$, if the design recommendation often used in Japan is considered (Japan Road Association, 2000). The attainment range of slope foot is determined by angle $\beta$ to both sides from the position of the release of rockfall shown in Fig. 1b. The angle 45 degree as the maximum empirical value is recommended with no relation to the topography of the scene. If the $190 \mathrm{~m}$ are compared with $90 \mathrm{~m}$ as the result of simulation with trees on the slope shown in Fig. 10a, this reveals a safe estimation.

Figure $10 \mathrm{~b}$ shows the distribution of velocities of the rockfalls that reached the mountainside of the road. When there were no trees on the slope, the maximum velocity ranges $35 \mathrm{~m} / \mathrm{s}$ to $45 \mathrm{~m} / \mathrm{s}$. When there were trees on the slope, the average velocity was relatively low, with $17 \mathrm{~m} / \mathrm{s}$, although the variation was large. No trajectory exceeded $40 \mathrm{~m} / \mathrm{s}$ as the maximum velocity.

For a crosscheck, if 45 degrees being as the average gradient of the slope and an equivalent coefficient of friction $\mu=0.35$ (Table 2) are assumed, the final velocity $47.2 \mathrm{~m} / \mathrm{s}$ at the slope foot would be obtained by Eq. (1). This velocity fits to the maximum value of $45 \mathrm{~m} / \mathrm{s}$ received from the simulation without trees on the slope. This shows that the rough estimation is on the safe side.

The simulation shows that taking into account the influence of trees on the slope can be useful and effective to plan protection measures for rockfalls. And, it has became clear that the trees on the slope have a significant influence on the trajectory of the rockfall. However, further research is required concerning specific constants for the contact between 


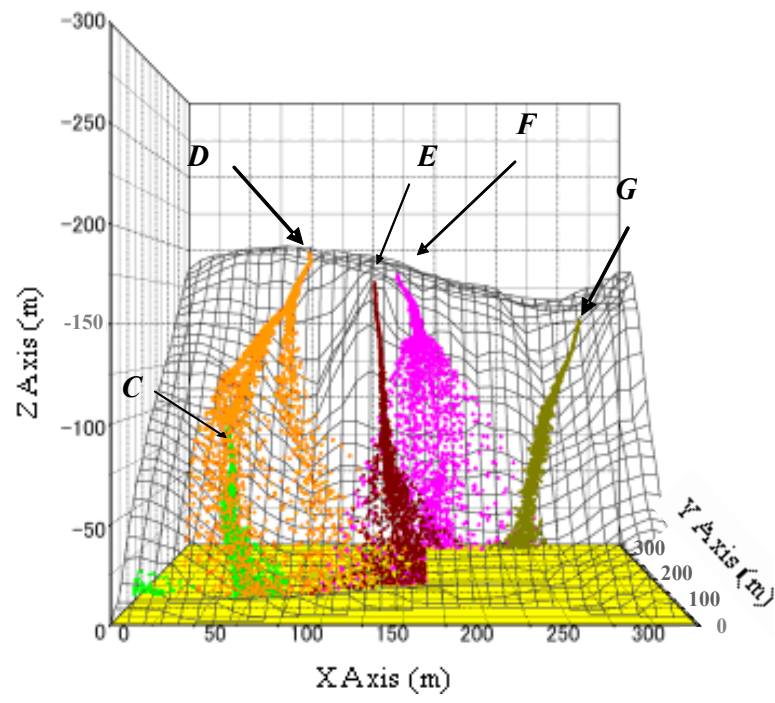

Fig. 11. Trajectories of rockfall.

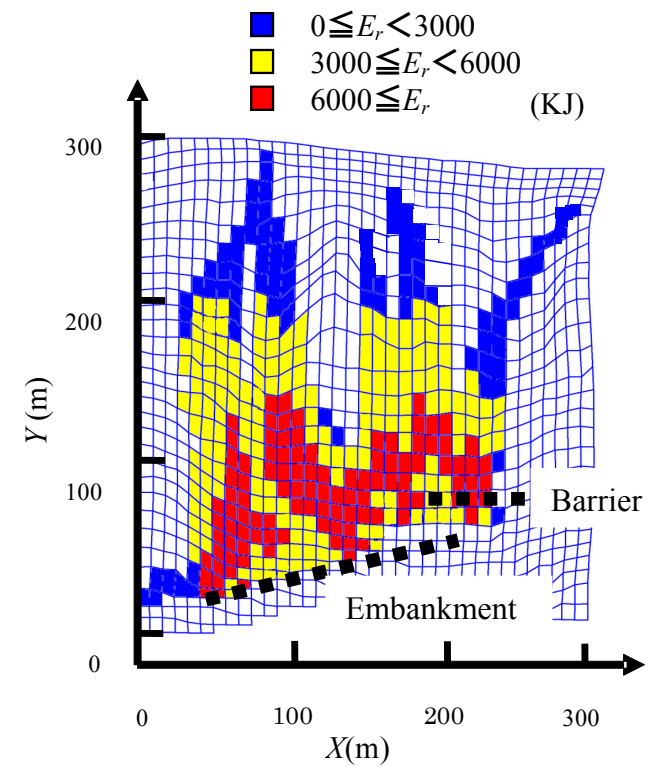

Fig. 12. Hazard map of rockfall.

\subsection{Protection measures}

trees and rock in order to apply this simulation method to various fields. Moreover, it is encouraged to research the utilization of vegetation on slopes, because it has a good influence on the natural environment and is also an effective measure against natural hazard on mountain slopes.

\subsection{Assessment of applied methods}

In order to efficiently guarantee the safety for passing vehicles, trains and inhabitants in dangerous rockfall zone, it is desirable to apply rational performance-based design methods for rockfall protection measures. It is generally difficult to know the occurrence probability of a rockfall. However, it would be possible to use sample rockfalls as a scenario derived from past data and field surveys. When a sample rockfall can be defined, according measure methods can be selected and designed. The use of a simulation method in order to estimate the rockfall risk is an effective support method to determine concrete measure. The rock used for analysis (see Fig. 9) had a mass, of $11000 \mathrm{~kg}$ being the largest one found in situ. Figure 11 shows the assumed release positions of rockfalls at five points C-G. Simulations were performed 100 times at each point. Due to the attainment width of the rockfalls at the road level, rockfalls can occur almost everywhere.

Figure 12 shows the hazard map of rockfalls according to the motion energy of the simulated rockfalls. Relatively small energies are observed in the upper part of the slope close to the release points and on the left side at the foot of the slope. Intotall and everywhere, large energies over $3000 \mathrm{~kJ}$ were observed at the lower end, even exceeding $6000 \mathrm{~kJ}$ in some areas.
The simulation results make it possible to plan and select the most suitable measures like the removal of dangerous rocks at the upper part of the slope or passive measures such as protection structures at the lower part of the slope. Table 3 shows the performance requirements of measures as an example according to the level of a rockfall and the importance of the protection structure.

If the road is designated "most important", for example, one selection is to construct a high performance rockshed that has a restorability limit state for even action level 3 . If the road is designated "important", the combination of different measures, such as embankment and retainment barrier, may be a rational selection having a restorability limit state for action level 2 and an ultimate limit state for action level 3.

On 25 March 2007, the Noto Peninsula Earthquake occurred. During this event, rockfalls occurred in many places. Also on the investigated slope, some large rockfalls occurred near from position E shown in Fig. 10. Figure 13 shows the rockfalls reaching the foot of the slope. The range of trajectories of real rockfalls was about $20 \mathrm{~m}$ larger than the results of rockfalls simulation without trees. The effectiveness of rockfall simulations with trees was verified. From investigation results at the scene and the results of rockfall simulations, considering the energies and jumping heights of rockfalls, it was determined to use a combination of an embankment with a length of $165 \mathrm{~m}$ along the coastline and a retainment barrier with a length of $80 \mathrm{~m}$ as shown in Fig. 12. The scope is to keep the serviceability limit state for over $90 \%$ of the expected rockfalls prospected. The embankment against rockfalls already had been constructed along the road side shown in Fig. 14 and a barrier is scheduled to be constructed. 
Table 3. Performance requirements for rockfall protection measures.

\begin{tabular}{llll}
\hline \multirow{2}{*}{ The action level of rockfall } & \multicolumn{2}{c}{ Extent of importance of protection structure for rockfall } \\
\cline { 2 - 4 } & Most important structure & Important structure & Usual structure \\
\hline Level 1 & Serviceability & Serviceability & Restorability \\
Frequent (few times per year) & limit state & limit state & limit state \\
Level 2 & Serviceability & Restorability & Ultimate \\
Rare (once or twice during design working life) & limit state & limit state & limit state \\
Level 3 & Restorability & Ultimate & Near collapse \\
(Probability is low but the energy is very high.) & limit state & limit state & \\
\hline
\end{tabular}

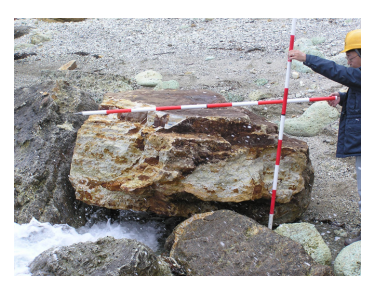

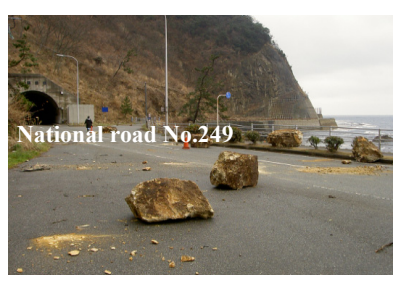

Rocks found under the slope $\mathrm{E}$

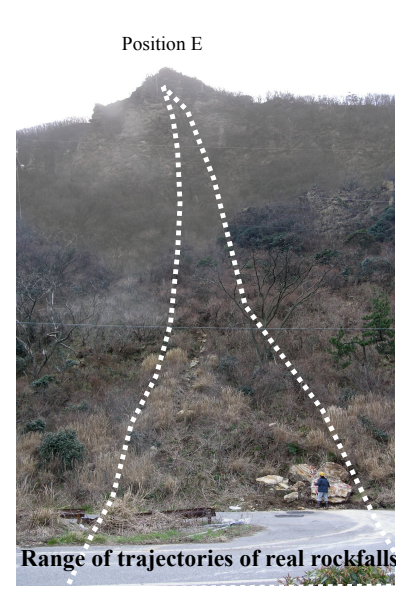

Slope under position $\mathrm{E}$
Fig. 13. Rockfalls as a result of Noto peninsula earthquake.

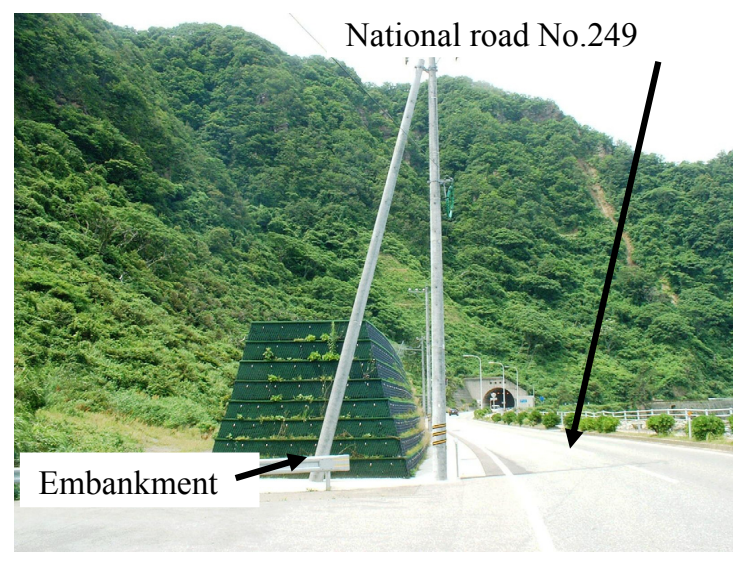

Fig. 14. Constructed embankment against rockfalls.

\section{Summary}

The analysis method of the motion of rockfalls on a threedimensionally modeled slope was investigated. This method probabilistically takes vegetation into consideration aiming an establishment of a practical simulation technique. The probabilistic treatment of trees as vegetation on the slope has been shown using three parameters, namely height, diameter and tree density. It has become clear that the influence of trees on slopes to the trajectory of a rockfall is comparatively large. The effectiveness of this simulation method with trees was verified by the comparison with rockfalls occurred during the Noto Peninsula Earthquake. The example of usage of simulation results for measures against rockfalls was also shown.

Edited by: K. Schellenberg

Reviewed by: three anonymous referees

\section{References}

Azzoni, A., G. L., Barbera, and Zaninetti, A.: Analysis and prediction of rockfalls using a mathematical model, Int. J. Rock Mech. Min., 32(7), 709-724, 1995.

Barrett, R. K.: Rockfall Modeling and Attenuate Testing, Colorado State Dept. of Highways, Denver, USA, 1989.

Delhomme, F.: Etude de comportment sous impact d'une structure pare-blocs en beton arme, pour obtenir le grade de garande de docteur del'universite de Savoie, March 2005.

Dorren, L. and Berger, F.: Stem breakage of trees and energy dissipation during rockfall impacts, Tree Physiol., 26, 63-71, 2005.

Dorren, L., Berger, F., Jonsson, M., Krautblatter, M., Mölk, M., Stoffel, M., and Wehrli, A.: State of the art in rockfall-forest interactions, Schweizerische Zeitschrift fr Forstwesen, 158(6), 128-141, 2007.

Impact Committee of Japan Society of Civil Engineers: Impact resistant design of rock-shed structures, Japan Society of Civil Engineers, 1998.

Ishikawa, N.: Recent progress on rock-shed studies in Japan, Proceedings of Joint Japan Swiss Scientific Seminar on Impact Load by Rock Falls and Design of Protection Structures, 1-6, 1999. 
Japan Road Association: Handbook of preventatives against rock falls, Japan Road Association, 2000.

Japan Railway Civil Engineering Association: Manual for preventive structures against rock falls, Japan Railway Civil Engineering Association, 1978.

Jonsson, M.: Energy absorption of trees in a rockfall protection forest, Diss. ETH No. 17214, 2007.

Kishi, N., Nakano, K., Matsuoka, K., and Nishi, H.: Field test on absorbing capacity of sand cushion, J. Struct. Eng., 39A, 15871597, 1993.

Komura, T., Muranishi, T., Nishizawa, K., and Masuya, H.: Study on parameters concerning impact of rockfall on field slopes and rock fall simulation method, Proceedings of the Fourth AsiaPacific Conference on Shock and Impact Loads on Structures, 345-352, 2001.

Masuya, H., Fukuda, N., and Tsutsumisita, K.: A development on the simulation of motion of rockfall on slopes, Journal of Structural Engineering, Japan Society of Civil Engineers, 43A, 15891596, 1997.

Masuya, H. and Yamamoto, M.: Load resistant factor of rock-sheds in heavy snow area, Proceedings of Joint Japan Swiss Scientific Seminar on Impact Load by Rock Falls and Design of Protection Structures, 121-127, 1999.

Masuya, H., Ihara, T., Onda, S., and Kamijo, A.: Experimental Study on Some Parameters for Simulation of Rock Fall on Slope, Proc. of the Fourth Asia-Pacific Conf. on Shock and Impact Loads on Structures, 63-69, 2001.

Masuya, H. and Nakata, Y.: Development of numerical model combining distinct element method and finite element methods and its application to rock shed analysis, Journals of Japan Society of Civil Engineers, No. 710/I-60, 113-128, 2002.

Masuya, H.: Performance based design of protection structure under impact action, Proceedings of International Symposium on Structures under Earthquake, Impact, and Blast Loading, 217$224,2008$.
Montani, S. S., Labiouse, V., and Descoeudres, F.: Action of falling blocks impacting rocksheds covered with a soil cushion, Proceedings of Joint Japan Swiss Scientific Seminar on Impact Load by Rock Falls and Design of Protection Structures, 51-57, 1999.

Pfeiffer, J., Higgins, D., and Turner, K.: Computer aided rockfall hazard analysis, Proceedings of 6th IAEG Congress, 93-103, 1990.

Schellenberg, K.: On the design of rockfall protection galleries An analytical approach for a performance based design, SVH, 186 pp., 2009.

Shi, G.: Forward and backward discontinuous deformation analysis of rock block systems, Proceedings of the International Symposium on Rock Joints, 731-743, 1990.

Sonoda, K.: A design procedure of rock sheds, Japan Society of Civil Engineers, J. Struct. Eng., 39A, 1563-1572, 1993.

Stevens, D.: RocFall: A tool for probabilistic analysis, design of remedial measures and prediction of rockfalls, A thesis submitted in confirmity with the requirements for the degree of Master of Applied Science, University of Toronto, Department of Civil Engineering, 1998.

Stoffel, M., Wehrli, A., Kuhne, R., Dorren, L. K. A., Perret, S., and Kienholz, H.,: Assessing the protective effect of mountain forests against rockfall using a 3D simulation model, Forest Ecol. Manag., 225, 113-122, 2006.

Subcommittee for Performance Based Design of Structures against Impact Action: Design method of structures under impact action by concept of performance based design, Japan Society of Civil Engineers, Structural Engineering Technical Series No. 52, 2007. Wieczorek, G., Snyder, J., Waitt, R., Morrissey, M., Uhrhammer, R., Harp, E., Norris, R., Marcus, I., Bursik, M., and Finewood, L.: Unusual July 10, 1996, rock fall at Happy Isles, Yosemite National Park, California, Geol. Soc. Am. Bull., 112(1), 75-85, 2000.

Yoshida, H., Masuya, H., and Oka, M.: Impulsive loading properties by falling stones on rock-sheds, Journals of Japan Society of Civil Engineers, No. 364/I-4, 461-470, 1985. 